Olga Trendak

University of Lodz, Lodz, Poland

\title{
Writing strategies employed by advanced learners of English- a questionnaire study
}

\section{Introduction}

The last few decades experienced an upsurge of interest in the broad field of language learning strategies. In course of time, researchers started to perceive the learner as a valuable source of information that could reveal a great deal about the processes involved in learning a language and the different skills inextricably linked with it. Researchers started to take greater interest in the thoughts and actions learners engage in when they focus on, for instance, speaking, learning vocabulary, reading or writing in their L2. In this article the author would like to elaborate on the increasingly popular area of writing strategies and the notions closely related to it.

As Manchón et al. (2007) suggest, studies into writing strategies should be perceived as part of a greater movement called process writing whose aim was to learn more about the mental actions L1 writers engage in when they compose. At the very beginning, that is in the 1980s, composition was regarded as "a goaloriented, recursive, cognitively-demanding, problem-solving task" (Manchón et al. 2007: 229). Since the 1990s stress has been placed on the social aspects of writing, which led many to believe that the process of composing is not only a cognitive but also communicative one and placed in a social context activity (Kent 1999). In course of time, researchers have taken interest in the actions taken by L2 writers to produce their texts. As many report, studies conducted in the field of 
L2 writing strategies have adopted a more socio-cognitive perspective as opposed to a cognitive perspective.

The purpose of the following paper is to address conceptual issues closely connected writing strategies. It will also discuss studies conducted into the use of L1 as a strategy employed by L2 learners, variables influencing writing strategy choice and the role of strategy training. In addition, the author will present the results of a study conducted among 100 advanced learners of English. The aim of the project was to examine the most and the least popular writing strategies employed by students at this particular level of foreign language advancement.

\subsection{Conceptual issues}

Although the term strategy very frequently appears in literature devoted to L2 writing, researchers still find it difficult to provide a conclusive definition of the notion. There are, however, numerous terms which appertain to actions identified as writing strategies. They include the following: writing behaviours, composing operations (Armengol-Castells 2001), writing techniques and procedures (Khaldieh 2000), composing processes (Zainuddin and Moore 2003), writing-process strategies (Sasaki 2004). In order to categorize these abundant terms referred to as writing strategies, Manchón (2001) introduced two types of characterization, a broad and narrow one, both of which will be briefly analyzed in further parts of the article.

\subsubsection{Broad characterization}

When discussing broad characterization one can distinguish two perspectives adopted in broad conceptualization: a learner-internal and a socio-cognitive one. The former deals with the actions L2 writers perform in order to compose a text. Studies conducted from this perspective have led to the categorization of writing strategies according to their level of generality. Therefore, planning, writing and revising, also known as macro-writing processes, are believed to represent a more general level. Writing strategies have also been categorized into subgroups. The first one includes steps taken when planning, for instance organizing; when writing, for example translating, rehearsing; revising, such as editing or evaluating to name a few. The second subgroup is associated with the task that is to be performed, in terms of planning and writing. In case of the former, the strategies mentioned include global and local planning or planning the content. As far as the latter is concerned, Manchón et al. (2007) provide examples of paying attention to the general organization or to linguistic aspects. 
When classifying writing strategies, researchers have adopted miscellaneous taxonomic approaches. In Victori's (1995) and Riazi's (1997) classification one may come across metacognitive strategies like planning, monitoring and evaluation. Wong (2005) differentiates between metacognitive, cognitive and affective writing strategies. Olivares-Cuhat (2002) mentions metacognitive, cognitive, compensation, social and affective writing strategies.

The socio-cognitive perspective, on the other hand, focuses on "the actions carried out by L2 writers to respond to the demands encountered in the discourse community where they write and learn to write" (Manchón et al. 2007: 232). Sociocognitive studies found a relationship between social and cognitive aspects which take part in the process of developing strategic competence of the L2 writer.

A study that is worth mentioning within this perspectiveis the one by Leki (1995) who set out to investigate writing strategies employed by 5 ESL university students. The instruments included interviews, observations and journals. The writing strategies that were identified in course of the study formed ten most important categories. The first one was called clarifying strategies which entailed consulting the teacher or other students in order to better understand the task to be performed, also asking for feedback. The second category was focusing strategies comprising, among others, rereading the task many times. Relying on past writing experiences was the fourth category that emerged as a result of the study. Other categories included taking advantage of first language/culture, using current experience or feedback, looking for models, using current or past ESL writing training, accommodating teachers' demands. As for the last category, the learner may adjust to the requirements or oppose them. The two remaining categories were resisting teachers' demands and managing competing demands. The last category consisted of a set of 5 subgroups. If the learner was to complete all the tasks, he/she was forced to take into consideration issues like course load, work load, the amount of investment made in a specific assignment, cognitive load and, finally, the demands of life.

\subsubsection{Narrow conceptualization}

In narrow conceptualization, on the other hand, researchers place emphasis on examining composing strategies from a cognitive, intra-learner perspective. It has been influenced by cognitive theories concerning L2 writing and the problemsolving paradigm in cognitive psychology. As Manchón et al. (2007) report, writing strategies function as two different phenomena that is control mechanisms and problem-solving devices (Roca de Larios 1999).

As for strategies perceived as control mechanisms, Cumming (1989) provides an example of a study conducted among Francophone Canadians enrolled in a bilingual course. The researcher noticed that more proficient writers used 
control strategies for activities like goal setting and managing their goals online. Therefore, their writing could be described in terms of a self-regulated process which, to quote Manchón et al. "entailed more problem-solving behaviour and thus greater use of problem-solving mechanisms to resolve the problems posed" (2007: 235). Less advanced writers, on the other hand, failed do deploy the right self-regulation strategies. As a result, they failed to monitor their writing and frequently did not know how to move on with their writing.

When treating strategies as problem-solving devices, Sasaki refers to writing strategies as "a writer's mental behaviour employed to achieve a goal in the ill structured problem solving (...) activity of writing" (2004: 541). Wong (2005) also adopts a similar definition of the notion of writing strategies. He describes them as the decisions made by the writer with a view to dealing with linguistic and rhetorical problems connected with the performed activity.

\subsection{Research into writing strategies}

Although the body of research into writing strategies has been abundant and has helped to learn more about L2 writers' strategic behaviour, certain issues still have not been completely resolved, particularly in terms of L1 and L2. There are researchers (Hinkel 2004, Lee 2005, Martinez 2005) who believe that L1 writing processes do not bear any resemblance to L2 writing processes, whereas others (Matsumoto 1995) oppose such a stance. What is more, some researchers (Scollon 1999) are convinced that differences in culture are the reason why L2 students encounter rhetorical organisation problems. Mu and Carrington (2007) state that culture exerts an impact on L2 writing, however, one should also bear in mind the genre of the task to be performed, L2 writers' cognitive development and interlanguage development. Other contentious issues concern strategy transfer. Some researchers (Friedlander 1990, Woodall 2002) concur that L1 composing strategies can be positively transferred into L2 writing. Others, on the other hand, opt for negative transfer (Wu 1995).

In their review of writing strategies, Manchón et al. (2007: 238) address certain methodological issues they observed. As for the first one, the number of participants, it ranges from one (McDonough and McDonough 2001) to 126 (Berman 1994). Among groups between 20 and 126 subjects, the most frequently applied instrument is a questionnaire, accompanied by text analysis. In smaller groups researchers adapted think-alouds, observations, interviews, self-reports or stimulated recalls. Another issue is the one of the subjects' age. Most studies into writing strategies focused on participants in their late teens, twenties but also thirties. The subjects, in the majority of cases, were university undergraduates or postgraduates. There were, however, studies that also focused on children (Chamot and El-Dinary 1999), high school students (Sengupta 2000), academics (Sasaki 2000) and professionals in the field (Levine and Reves 1998). 
Another area which Manchón et al. (2007) included in their review appertained to the subjects' L1 and L2. The researchers found that although the majority of research projects focused on subjects learning English as their second or foreign language, there were also studies that concentrated on other languages, like French (Brooks-Carson and Cohen 2000), German (Chenoweth and Hayes 2001), Spanish (Woodall 2002), Japanese (Hatasa and Soeda 2000), Greek (McDonough and McDonough 2001), Hebrew (Levine and Reves 1998, Schwarzer 2004) or Arabic (Khaldieh 2000). The subjects' level of linguistic advancement was assessed in different ways, according to their institutional status, which refers to the level necessary to enrol in a course; teachers' evaluation but also standardized tests.

Since it is not possible to address all these issues in this paper, the following sections will be devoted to a selected range of issues like the variables affecting writing strategy choice and use, the use of L1 in the process of L2 writing and the role of strategic intervention.

\subsubsection{Factors influencing writing strategies}

The studies conducted so far into the area of writing strategies have shown that there are several variables that exert an impact on learners' use and choice of composing strategies. They fall within two main types, namely writer-internal variables and writer-external ones (Figure 1 below).

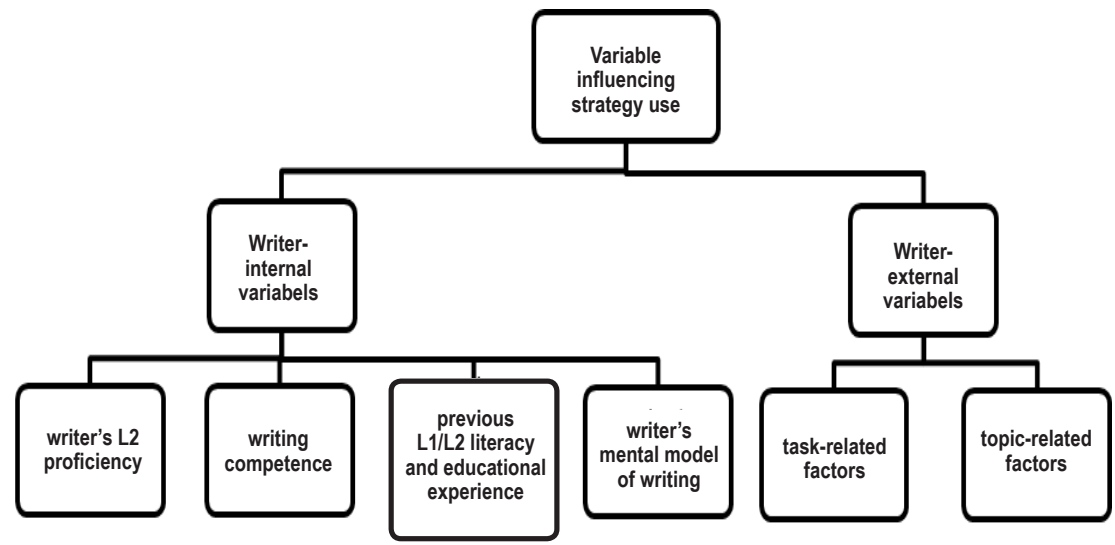

Figure 1. Variables affecting the use of writing strategies

As for the former, learners' L2 proficiency (Cumming 1989, Sasaki 2000, Sasaki 2004) and their writing competence (Raimes 1987, Cumming 1989) are the two most often mentioned factors. Researchers also mention previous L1/ L2 literacy and educational experience (Cumming 1989, Porte 1995, Sasaki 2000, Sasaki 2004, Manchón et al. 2007) as well as the writer's mental model of writing, 
a term which appertains to the beliefs that stand behind learners' writing. Other research findings revealed that more advanced L2 writers are more likely to take risks when creating a more extensive and sophisticated piece of writing (Khaldieh 2000), whereas less proficient writers place more emphasis on areas such as grammatical aspects of the text (Kasper 1997).

When discussing writer-external variables, researchers mention two most significant factors: task- and topic-related ones. Factors associated with the task include issues like the sort of the task to be performed or the time the learner has at his/her disposal. Some tasks constitute a greater cognitive challenge than others. Cumming (1989) states that writing an argumentative essay involves taking considerably more decisions than, for instance, writing a letter. Sasaki (2004) found that when students had less time for their writing, they more frequently resorted to local planning. The study also revealed that time affected the employment of translation. Manchón et al. (2007) agree that while L1 may appear very useful when writing, translating the produced content into the L2 may appear too time-consuming if the time is limited. Topic related factors (Friedlander 1990), on the other hand, are connected with, for instance, learner's familiarity with the topic.

\subsubsection{The use of $\mathrm{L} 1$}

Another area of interest is the use of L1. It is believed to be very frequently used in the process of $\mathrm{L} 2$ writing during activities such as planning, writing or revising (Manchón et al. 2007). Research has shown that when engaged in writing in the target language, learners very frequently resort to planning their ideas in their mother tongue (Sasaki and Hirose 1996, Hu 2003, Wolfersberger 2003). In fact, the use of L1 at the stage of planning is regarded as beneficial since learners produced much more sophisticated and longer plans. The texts generated are also better organized and more detailed. As far as writing is concerned, L1 is employed to produce the text, deal with stylistic as well as linguistic problems, and to organize the essay (Manchón et al. 2007).

However, using L1 for text writing has triggered some deal of controversy. There are researchers, like for instance Whalen and Ménard (1995) who are of the opinion that L1 in L2 writing places too much strain on the learners. Translating a text generated in the mother tongue may appear extremely time-consuming and spark off additional problems language-wise. To make matters worse, text translation may, in some cases, hinder the creation of new ideas (Manchón et al. 2007). However, this frequently characterizes less advanced writers. The more proficient ones translate their texts from L1 to L2 less often (Sasaki and Hirose 1996). As far as the product perspective is concerned, Kobayashi and Rinnert (1992) found that the texts produced initially in the L1 and later on translated into the L2 were much better in terms of the content, organization and, surprisingly, 
language. The texts abounded in sophisticated vocabulary and complex structures. What is more, L1 is frequently employed by advanced L2 writers for stylistic and linguistic purposes and also to organize and structure the text (Wang and Wen 2002, Woodall 2002). According to some studies (Manchón and Roca de Larios 2005), L2 writers back-translate the texts they generated into their L1 with a view to, among others, checking the solutions they came up with or the overall appropriateness of their ideas. More advanced L2 writers also engage in the process of evaluation in their L1.

Several studies into L2 writing strategies have revealed that learners employ their L1 for monitoring (Wang and Wen 2002, Woodall 2002). Some researchers are of the opinion that the use of L1 for monitoring does not decrease, even if learners' L2 proficiency increases, which in Manchón et al.'s view may be connected with the "factors uncovered in studies of bilingualism, where it appears that the two languages of a bilingual individual can be used to play different social roles and also with Vygotskyan notions of private speech" (2007: 242).

Manchón et al. believe that the reason why even advanced L2 writers switch to their L1 for activities like conceptualization, planning, organizing, monitoring the writing process or task evaluation is the fact that "as fluency increases and the generation process becomes more automatic, more mental capacity is freed to attend to higher levels of processingplanning, organization, solving rhetorical, and discourse problems - which may continue to take place in the mother tongue because of the deeper processing involved, particularly if the task presents high cognitive demands" (2007: 242). The researchers do admit, however, that the strategy of deploying L1 may also be affected by the learner's beliefs concerning high quality writing, their identity, previous experience, etc.

The use of L1 has appeared to be a significant tool for problem-solving which L2 writers intentionally employ for tasks such as planning, organizing, generating and revising the text produced, expressing the intended message, evaluating and improving the content and language and for monitoring (Manchón et al. 2007).

\subsubsection{Strategy training}

Researchers are of the opinion that one of the reasons why language learning strategies should be implemented into regular classes is that they play a significant role in the development of learners' autonomy. Language learners should be cognizant of the existing strategies as it may trigger more effective learning. Dansereau states that "by not stressing learning strategies, educators in essence discourage students from developing and exploring new strategies, and, in so doing, limit students' awareness of their cognitive capacities. This lack of awareness obviously limits an individuals' ability in a situation requiring new learning strategies" (1978: 14, quoted in Droździał-Szelest 1997: 82). Rubin et al. (2007) add that promoting strategies increases learners' motivation and 
performance and provides them with the necessary knowledge to continue their autonomous learning. The best way to increase learners' knowledge of language learning strategies is by means of strategy training. Although there have been many studies examining the efficacy of strategic intervention, many agree that in terms of writing strategies, this area is still an under-researched one and requires more comprehensive investigation.

In many studies the effectiveness of strategic intervention was operationalized as the impact it exerted in the learners'stratey use (Sasaki 2000), their mental model of writing (Cresswell 2000, Sengupta 2000, Ching 2002) and the quality of learners' writing before and after receiving the treatment. As Manchón et al. (2007) report, the results of the studies prove that strategy training had a positive influence on the manner in which L2 writers performed a task. Their confidence and autonomy was also boosted as a result of the training they underwent. What is more, the quality of learners' essays was affected by the training. Sasaki (2004), who investigated the impact of strategy training among university students, found that in course of time, the beneficial impact of the treatment disappeared if the subjects did not engage in any additional writing practice.

Manchón (2007) adds that for the training to be efficacious, certain requirements must be met. To start with, the teacher should be well qualified and possess the necessary knowledge to implement the treatment. Furthermore, the duration of the training should also be taken into account. The treatment should last at least ten weeks as only this way can it yield satisfying results. Lastly, the training should include a metacognitive component, so valued by many researchers. The knowledge of one's thinking processes is perceived as very important as it provokes reflection and makes the learner think about the next steps that should be taken in the course of task performance. Learners who possess metacognitive awareness are able to perceive and comprehend the similarity between current and previous activities. Examples of studies conducted in this vein include those in which training was provided to learners who wanted to become more successful writers (Macaro 2001).

Oxford (1990: 204-208) believes that when conducting the training, the teacher should bear in mind a few issues. Firstly, the teacher should determine the learners' needs and the time available. It is vital to take into consideration learners' age, level of proficiency, social and cultural background as well as their strengths and weaknesses. It is also advisable to carefully observe the strategies learners use and which they may benefit from most. The questions Oxford (1990: 204) suggests when considering the implementation of strategy training include:

- Is there a wide gap between the strategies they have been using and those you think they need to learn?

- How do these students view their roles as language learners?

- Do they take responsibility, or will you need to help them change their attitudes about learning? 
- Have you given the learners a chance to express their desires about strategies they might like to learn?

The next stage entails proper selection of the strategies to be taught. They ought to match learners' needs like, among others, their age, level of linguistic advancement, their social and educational background. What is more, the teacher should consider integration of strategy training which entails making it a part of regular classes and not a separate component. Oxford argues that if the training is closely connected with the process of language learning, learners have a chance to observe and comprehend how strategies can be deployed in a meaningful context. Motivational issues also have to be borne in mind as the teacher should be able to motivate their students to actively participate in the classes. Oxford (1990) adds that encouraging students to select the strategies they want to learn about may prove effective as learners will feel they contributed to the development of the lesson and that not everything was imposed on them by the teacher. Preparing materials and activities is another issue to remember. At this stage the teacher should remember about stimulating and appealing handouts that would attract learners' attention and spur them to active participation.

Oxford also places a great deal of emphasis on completely informed training as students should know why they are taking part in the treatment, how they can employ the new strategies they learnt in different situations and what benefits they will bring. Finally, in the last stage of the treatment, the teacher should evaluate the conducted training and assess its effectiveness.

Rubin et al. (2007: 142) also mention vital steps which each strategy training should include to yield satisfying results. These are as follows:

1. raising awareness of the strategies learners are already using;

2. teacher presentation and modelling of strategies so that students become increasingly aware of their own thinking and learning processes;

3. multiple practice opportunities to help students move towards autonomous use of the strategies through gradual withdrawal of the scaffolding;

4. self-evaluation of the effectiveness of the strategies used and transfer of strategies to fresh tasks.

As can be seen, the metacognitive component plays a very important role in strategic intervention. Learners should be made aware of the notion of strategies and their function in the foreign language classroom. There are many ways of raising learners' awareness. The quickest and easiest one is to encourage students to take part in a short discussion about strategies. Learners can exchange their ideas about the strategies they use and also share those they find most effective with other, sometimes less advanced learners. The teacher may also implement questionnaires, though their content should be adjusted to learners' proficiency level and age, which may be time-consuming on the teacher's part. Another way of increasing learners' awareness of strategies is called focus groups. It is an 
activity in which learners concentrate on a particular skill, for example writing and discuss the aims connected with this skill, like writing a CV, a personal letter, a review, etc. Then, the teacher divides the whole class into smaller groups which select one goal and try to address the difficulties associated with achieving it and the possible solutions. Journals or diaries can also be an effective tool for raising awareness of strategies, although it may appear time-consuming.

\section{The study}

Learning more about the subjects' strategic behaviour is extremely useful for teachers in general as it still need further classroom time. Thanks to such knowledge, the teacher. What is more, being more in control of their writing behaviour might boost L2 learners' confidence and additionally spur them into action. Additionally, knowledge about strategies is to make learning easier, more enjoyable and, hopefully, more satisfying.

\subsection{The aim of the study}

The purpose of the undertaking was to gain greater insight into the writing strategies employed by advanced learners of English. The author wanted to examine the strategies the subjects deploy and the frequency of strategy use when they engage in the process of writing in their target language. In order to identify the strategies, the author adopted Oxford's (1990) taxonomy of strategies which includes memory, cognitive, compensation, metacognitive, affective and social strategies.

\subsection{The subjects and the context}

There were 100 subjects, aged 17-24, participating in the study. The number of subjects could have been higher but is still satisfying taking into account the fact that holidays were approaching and matura exams had already started That is why, many students were absent from classes during the time of the study. All of the subjects attended a CAE course at a private language school. Although the students were classified as $\mathrm{C} 1$ level, there were students who clearly lagged behind and those who did much better and outdid their classmates. The reason why this particular educational setting was chosen was the fact that the author was professionally bound with the school. Such a state made it fairly easy to gather the necessary data appertaining to writing strategies among a group that constituted as many as 100 students representing a C1 level of advancement. 


\subsection{The instrument}

The choice of the instrument and the whole procedure was influenced by the amount of time the author had at her disposal. Since the end of school year was looming and there was a risk that certain students would fail to attend the final lessons, steps had to be taken to collect the necessary data in a quick and efficient way among as many students as possible. Therefore, for the sake of the study, the author resolved to make use of a questionnaire which was a part of a larger one created by Cohen et al. (2002). The questionnaire the subjects were to complete contained ten questions referring strictly to writing strategies, whereas Cohen et al.'s questionnaire also entailed other types of learning strategies like, for instance, translation or listening strategies. The questions included the following:

- I practise writing the alphabet in the new language.

- I plan how I am going to write an essay, monitor to see how my writing is going and then check to see how well I wrote what I wanted to.

- I make an effort to write different kinds of texts (e.g. letters, personal messages, etc.).

- I often take class notes in the target language.

- When I cannot think of the correct expression to write, I usually find a different way to express the idea, for example I use a synonym or describe the idea.

- I review what I have already written before continuing to write new material in an essay.

- I use reference materials such as a glossary, a dictionary to help me find words in the target language.

- I postpone writing until I have got my own ideas.

- I revise the essay once or twice to improve the language and content.

- I look for ways to get feedback from others (teachers, fellow students, etc.). The subjects were to write how often they employed a certain strategy. The possible answers were as follows:

- always or almost always,

- quite often,

- sometimes,

- rather rarely,

- never or almost never.

The reason why the author used this particular type of instrument, as was briefly mentioned above, was the fact that it can easily be distributed among a large group of subjects and data analysis in not time-consuming when compared with other methods of obtaining information. Additionally, since the questionnaire was anonymous, the subjects were not placed under any pressure which can frequently exert a negative impact on the outcome of the study. Finally, since there questionnaire lacked open-ended questions, the data obtained were subject to quantitative analysis. 


\section{Results and discussion}

As far as formal practice with the writing system is concerned, which was mentioned in the first question, the subjects were extremely reluctant to deploy this writing strategy. $45 \%$ of the students surveyed admitted they never or almost never practise the writing system and as many as 35\% do it rarely. Out of the 100 students questioned, only 2 practise the writing system always or almost always and 3 do so quite frequently. Of course, the disadvantage of this question is the fact that it is culture-based and the results are likely to be affected by learners' surroundings. The English alphabet does not require as much practice and effort as, for instance, the Cyrilic or the Chinese alphabet, which might explain why so many students decline to practise it. The answers show that, in the majority of cases, the subjects do not perform any spelling activities on their own.

In the second question, the subjects were to say whether they plan, monitor and check their writing. The results obtained show that only $22 \%$ of the students questioned always or almost always deploy this metacognitive strategy, $37 \%$ plan, monitor and check their writing quite often. However, as many as 27 students only sometimes make use of this strategy. Such results are somewhat disturbing since, when focusing on writing in the TL, teachers frequently stress the importance of planning, monitoring and checking the essay to be submitted. Apart from teachers' guidance, students are frequently offered tips how to write in coursebooks. Almost every coursebook is supplied with a section devoted to improving writing skills and one may frequently encounter information about careful planning, monitoring the essay and checking it.

At this point it is worth mentioning that the question is not straightforward as it addresses too many issues at the same time. In fact, it encompasses three different strategies: planning, monitoring and revising which do not always have to go together. While students may engage in planning, they do not necessarily have to make use of monitoring or checking. They might also revise their written work but that does not mean they planned or monitored their essay. Therefore, the question might lead to some degree of bafflement among the subjects and, to make matters worse, it may even distort the results of the study to some degree.

As for the third question, the subjects were to say how frequently they write different kinds of texts, like notes, letters or personal messages in English. The data obtained show that the subjects participating in the study are not too eager to practise naturalistically, outside the formal setting. $7 \%$ of the subjects admitted they always or almost always deploy this strategy and 31\% do so quite often. Disappointingly, as many as 31 students only sometimes practise their writing naturalistically. Although the subjects were not asked about the reasons, one may only assume that the most obvious one is laziness and lack of motivation. With all the technologies they have at their disposal, it is a shame that many students do not even bother to use them to enhance their, among others, writing skills. An 
additional reason why students do not use this strategy is the fact that they are simply not cognizant of the beneficial role of natural practice. Some of them are fully satisfied with the state and quality of their writing and, therefore, do not feel any need to improve it. Furthermore, some students may be convinced that there are more important skills than writing like, for instance, speaking and devote more time to boosting this particular area.

The next point in the questionnaire depicted that the overwhelming majority of the subjects, all together $77 \%$, engage in the cognitive strategy of note-taking on a regular basis. This finding is definitely an optimistic one from the teacher's perspective. $14 \%$ of the subjects surveyed sometimes take their notes, $5 \%$ do so rarely and only $4 \%$ never do so. One may assume that students take notes not to forget the most significant material from the lesson. Whatever the reasons are, the results are optimistic as thanks to note-taking students have an extra opportunity to practise the writing system of the target language.

In the fifth question the subjects were asked about their use of synonyms or circumlocution when they cannot think of the correct expression to write. Half of the respondents always or almost always employ this compensation strategy and $36 \%$ do it quite often. All together, there are 86 students who use synonyms or circumlocution on a regular basis. There was only one subject who never does so and 14 who rarely use this strategy. These results are rather satisfying as they show that when faced with an obstacle, such as a word missing in their mental dictionary, the subjects do not give up and try to continue the task they were involved in. Sadly enough, it is not always the case as, having encountered some sort of linguistic hindrance, many language learners frequently admit they abandon the message they wanted to convey, even if it is tantamount to producing an essay of lower quality.

The next point focused on a metacognitive strategy of reviewing. When giving useful tips to students, many teachers frequently remind them to, among others, review what they have already written in order to improve it. However, only $18 \%$ of the students questioned always review their essays, 33\% do it quite often and $34 \%$ sometimes. Again, the results might disappoint to some extent, as learners are often told analyze their writing and to devote more time and energy to it. The data obtained might however imply that students prefer to rely on what they have already written rather than go back to the beginning and read the text once or twice which they often find a waste of time on their part. On the other hand, though, out of the 100 subjects questioned, there was only one who openly admitted to never reviewing his/her written work, which, on the whole, is a good sign.

The cognitive strategy of using reference materials was referred to in the seventh question. The overwhelming majority of subjects, $75 \%$, said they employ additional resources, such coursebooks, dictionaries, collocations or the Internet, when they wish to find a missing word in the target language. Only 8 students never or almost never opt for additional sources and 7 do so rarely. Although 
jumping to conclusions should be avoided, it seems possible that these subjects might simply think that their range of vocabulary is so vast that there is no need to extend it through additional materials. Others might simply skip the words missing in their mental dictionary and rely on synonyms they know well. On the whole, these results show how determined students are when they want to find a missing element that would complete their writing.

The eighth question appertained to a metacognitive strategy of postponing writing until the student has his/her own ideas. The results show that $23 \%$ of students always or almost postpone their writing and $28 \%$ do so quite often. On the one hand, the results may be slightly disturbing, as bearing in mind the amount of time teachers dedicate to promoting careful analysis of the task, one would expect students to carefully analyze the task and the issues associated with it before actually completing it. Surprisingly, though, not many students are that eager to engage in, for instance, brainstorming prior to writing their essays. Such an attitude to writing might explain why some texts are written in a chaotic and slapdash manner. On the other hand, though, learners might simply believe that the ideas will eventually crop up during and not before the process of writing, which frequently is the case.

Another metacognitive strategy was referred to in the ninth point. They students were asked whether they revise their written work in order to improve it language- and content-wise. Surprisingly enough, $17 \%$ of respondents never or almost never do so and 20\% rarely. Only 33\% of the subjects questioned revise their essays on a regular basis and $30 \%$ only sometimes decide to do so. The results are far from satisfying, especially since students are very often told to go through what they have written before they hand it in to the teacher. The results in this particular point may be connected with a previous question addressing the issue of planning, monitoring and checking. If students fail to plan their writing, they may end up having not enough time at the end of their work for further revision. Hence, they do not manage to read their texts one more time and as a result fail to improve the content and the language, which frequently exerts a negative impact on the final grade and on the quality of the text produced.

The last question dealt with a social strategy. The subjects were asked whether they look for ways to get feedback from others, for instance their peers, teachers or native speakers. Surprisingly, the vast majority of students (33\%) never or almost never cooperate with others. 34 people declared they do so but rather rarely. There was only one person who always looks for feedback from others and 12 who do it quite often. As in previous questions, there may be several reasons behind these results. Lack of knowledge about the beneficial role of cooperation maybe one of them. Some students may simply not know that exchanging ideas with others may positively affect their L2 writing. What is more, some students may want to rely solely on themselves and, therefore, reject the thought of working with peers, even if they represent a higher level of language advancement and could in fact prove very helpful. Others are simply too shy to ask for some tips and resort to different 
sources of obtaining information like coursebooks, notes or the Internet which do not require any interaction whatsoever. Undeniably, more encouragement on the teachers' part would also help students to seek help or advice form others.

\section{Conclusion}

When examining the most popular strategies the advanced learners of English participating in the study employ when they write in the target language, one may distinguish the following: using circumlocution or a synonym, note-taking and using resources, all of which are cognitive strategies (Figure 2 below).

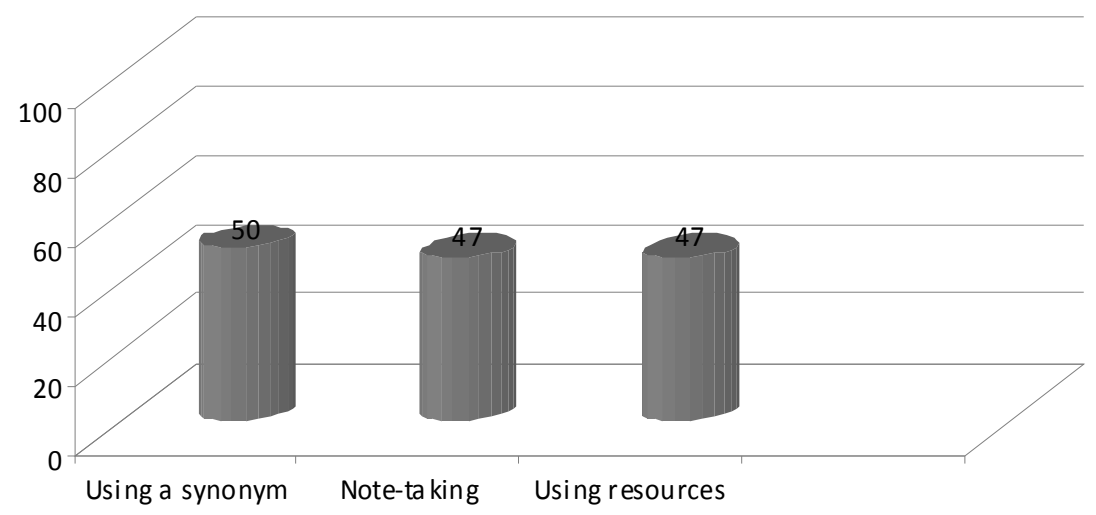

Figure 2. The most popular writing strategies

By contrast, the strategies which students favour the least are formal practice with the writing system and cooperating with others (see Figure 3 below).

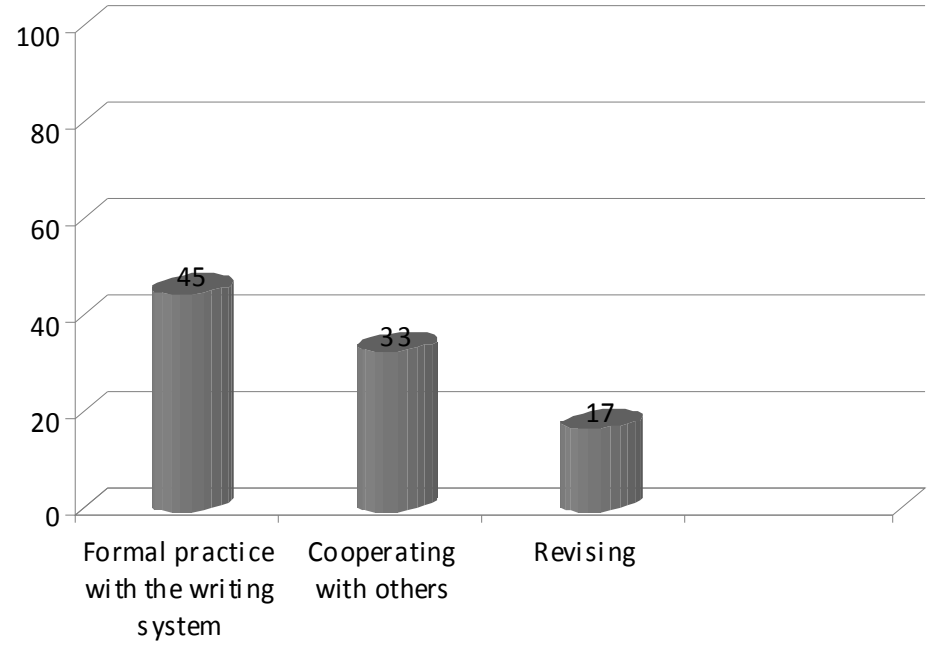

Figure 3. The least popular writing strategies 
In the light of the results obtained in the study, it might be profitable to encourage peer cooperation as obtaining help from others may enhance the quality of students' writing and provide them with new ways of improving their writing skills. Moreover, teachers might also try and focus on the strategy of formal practice with the writing system of English, which might, hopefully, decrease the number of spelling errors, so frequent among even advanced students. To improve the quality of their essays, students should be regularly reminded to plan, monitor and evaluate their work. It should also be borne in mind that teachers should remember about the popular writing strategies and promote their employment on a regular basis.

However, teachers often encourage learners to make use of all of the above mentioned strategies and, unfortunately, the quality of students' essays still leaves much to be desired. Some learners seem impervious to teachers' comments and advice dismissing it as irrelevant. Therefore, introducing strategy training might yield satisfying results. There are certain requirements that should be met if the training is to be efficacious. Many researchers believe that strategic intervention should comprise two stages in order to be highly effective. In the first one, the teacher should focus on raising learners' general awareness of the notion of a learning strategy by means of discussions, pair-work or group-work. Learners can exchange their ways of learning and also the ways in which they organize their writing in the target language. The second stage should be devoted to proper strategy training with emphasis placed on specific strategies of interest to the teacher and the students.

Summarizing the paper, the author admits that the data gathered in this study are by no means conclusive. There are many obstacles and limitations that need to be surpassed in order to gain greater insight into the writing strategies advanced learners of English employ. To start with, it would be advisable to include a wider range of strategies that students could choose from in the questionnaire. The strategies present in the survey were rather limited in their scope, which makes generalizations about the results obtained not feasible. Furthermore, introducing open-ended questions might prove to be very useful as they could reveal more about the subjects' preferences for certain writing strategies. In fact, the questionnaire itself abounds in weaknesses, which affects the whole study. It should also be mentioned that this particular instrument is not always suitable for data collection. Since the questions should be presented in a straightforward manner, the information gathered may be simply superficial. In addition, the questionnaire does not always manage to examine an issue comprehensively enough (Dörnyei 2007). Therefore, employing other instruments like, for instance, learner diaries might contribute to greater data collection. This particular tool could in fact be an invaluable source of information for the teacher and, surprisingly for the students as well. Learners might be asked to share their reflections about the process of writing in the target language. They may focus on their strengths, 
weaknesses, writing experience or attitude towards writing. In order to generate as much relevant information as possible, introducing additional questions, strictly connected with writing strategies, to the diary format could result in abundant and pertinent entries.

In conclusion, research in writing strategies has been affected by numerous theoretical frameworks, which has led to numerous taxonomies and conceptualizations of composing strategies. What is more, there have been many aattempts to examine and operationalize this construct. When analyzing the abundant studies conducted so far into writing strategies, one may notice the following:

1. L2 writers implement a wide range of general and specific strategic actions in their attempt to learn to write and to express themselves in writing in and L2;

2. given the socio-cognitive dimensions of composing, the L2 writer's strategic behaviour is dependent on both learner-internal and learner-external variables;

3. the writer's strategic behaviour is mediated by the instruction received and can be modified through strategy instruction (...) (Manchón et al. 2007: 248).

Although the existing body of research into composing strategies has been abundant, there are still several issues that need further investigation. To start with, the area of strategy training needs more attention. If future studies are to be a source of invaluable information, researchers need to be more consistent in terms of the choice of the theoretical framework present in their projects. Manchón et al. express their disapproval of studies which result in the creation of "theoretical and decontextualized taxonomies of strategies" (2007: 248). What is more, in order to make the results more generalizable, more emphasis should also be placed on younger and less advanced L2 writers as they constitute a large number of students learning to write in the target languages. Other issues that need to be taken into consideration are related to data analysis and include validity, reliability and categorization. Although still a lot needs to be improved, the research in the field of writing strategies has been extensive and has, most surely, helped researchers and theoreticians gain greater insight into the composing strategies their learners employ.

\section{References}

Armengol-Castells, L. 2001. Text-generating strategies of three multilingual writers: A protocolbased strategy. Language Awareness, 10, 91-106.

Berman, R. 1994. Learner's transfer of writing skills between languages. TESL Canada Journal, 12, 29-46.

Brooks-Carson, A.W. and Cohen, A.D. 2000. Direct vs. translated writing: Strategies for bilingual writers. In B. Swierzbin, F. Morris, M.E. Anderson, C.A. Klee and E.Tarone (Eds.), Social and Cognitive Factors in Second Language Acqusition. 2000, pp. 397-423. Amsterdam: University of Amsterdam Press. 
Chamot, A.U. and El-Dinary, P.B. 1999. Children's learning strategies in language immersion classrooms. Modern Language Journal, 83, 319-338.

Chenoweth, N. and Hayes, J. 2001. Fluency in writing: Generating text in L1 and L2. Written Communication, 18, 80-98.

Ching, L.C. 2002. Strategy and self-regulation instruction as contributors to improving students' cognitive model in an ESL program. English for Specific Purposes, 21, 261-289.

Cohen, A.D., Oxford, R. and Chi, C. 2002. Language strategy use survey. In A.D. Cohen and S.J. Weaver (Eds.), Styles and Strategies-Based Instruction: A Teacher's Guide. 2006, pp. 68-74. Minneapolis, MN: Center for Advanced Research on Language Acquisition, University of Minnesota.

Cresswell, A. 2000. Self-monitoring in student writing: Developing learner responsibility. ELT Journal, 54, 235-244.

Cumming, A. 1989. Writing expertise and second language proficiency. Language Learning, 39, 81-141.

Dansereau, D.F. 1978. The development of learning strategies curriculum. In H. O'Neill (Ed.), Learning Strategies, pp. 1-29. San Francisco, California: Academic Press.

Dörnyei, Z. 2007. Research Methods in Applied Linguistics. Oxford: Oxford University Press.

Droździał-Szelest, K. 1997. Language Learning Strategies in the Process of Acquiring a Foreign Language. Poznań: Motivex.

Friedlander, A. 1990. Composing in English: Effects of a first language on writing in English as a second language. In B. Kroll (Ed.), Second Language writing: Research Insights for the Classroom, pp. 109-125. New York: Cambridge University Press.

Hatasa, Y. and Soeda, E. 2000. Writing strategies revisited: A case of non-cognate L2 writers. In B. Swierzbin, F. Morris, M.E. Anderson, C.A. Klee and E.Tarone (Eds.), Social and Cognitive Factors in Second Language Acqusition. pp. 375-396. Somerville. MA: Cascadilla Press.

Hinkel, E. 2004. Teaching Academic ESL writing: Practical Techniques in Vocabulary and Grammar. Mahwah, NJ: Erlbaum Associates.

$\mathrm{Hu}$, J. 2003. Thinking languages in L2 writing: Research findings and pedagogical implications. TESL Canada Journal 21: 39-63.

Kasper, L.F. 1997. Assessing the metacognitive growth of ESL student writers. TESL-EJ Journal, 3, 1-20.

Kent, T. 1999. Post-Process Theory: Beyond the Writing-Process Paradigm. Carbondale: Southern Illinois University Press.

Khaldieh, S.A. 2000. Learning strategies and writing process of proficient vs. less-proficient learners of Arabic. Foreign Language Annals, 33, 522-533.

Kobayashi, H. and Rinnert, C. 1992. Effects of first language on second language writing: Translation versus direct composition. Language Learning, 42, 183-215.

Lee, S.-Y. 2005. Facilitating and inhibiting factors in English as a foreign language writing performance: A model testing with structural equation modelling. Language Learning, 55, 335-374.

Leki, I. 1995. Coping strategies of ESL students in writing tasks across the curriculum. TESOL Quarterly, 29, 235-260.

Levine, A. and Reves, T. 1998. Data collecting on reading-writing strategies: A comparison of instruments: A case study. TESL-EJ Journal, 3, 1-11.

Macaro, E. 2001. Learning Strategies in Foreign and Second Language Classrooms. London: Continuum.

Manchón, R.M. 2001. Trends in the conceptualization of second language composing strategies: A critical analysis. International Journal of English Studies, 1, 47-70.

Manchón, R.M. and Roca de Larios, J. 2005. Forms and functions of backtracking in L2 writing: A study of Spanish EFL learners at different proficiency levels. Paper presented at theXXIII Conference of the Spanish Association of Applied Linguistics, Palma de Mallorca, Spain, March 10-12. 
Manchón, R.M., Roca de Larios, J. and Murphy, L. 2007. A review of writing strategies: Focus on conceptualizations and impact of first language. In A.D. Cohen and E. Macaro (Eds.), Language Learner Strategies, pp. 229-250. Oxford: OUP.

Martínez, I. A. 2005. Native and non-native writers' use of first person pronouns in the different sections of biology research articles in English. Journal of Second Language Writing, 14: 174-190.

Matsumoto, K. 1995. Research paper writing strategies of professional Japanese EFL writers. TESL Canada Journal, 13, 17-27.

McDonough, J. and McDonough, S.G. 2001. Composing in a foreign language: An insider-outsider perspective. Language Awareness, 10, 233-247.

$\mathrm{Mu}, \mathrm{C}$. and Carrington, S. 2007. An investigation of three Chinese students' English writing strategies. Teaching English as a Second or Foreign Language, 11, 1-23.

Olivares-Cuhat, G. 2002. Learning strategies and achievement in the Spanish writing classroom: A case study. Foreign Language Annals, 35, 561-570.

Oxford, R. 1990. Language Learning Strategies: What Every Teacher Should Know. Boston: Heinle \& Heinle.

Porte, G. 1995. Estrategias de revisión en expressión escrita en lengua inglesa como segunda lengua. Unpublished doctoral thesis, University of Granada, Spain.

Raimes, A. 1987. Language proficiency, writing ability, and composing strategies: A study of ESL college student writers. Language Learning, 37, 439-467.

Riazi, A. 1997. Acquiring disciplinary literacy: A social-cognitive analysis of text production and learning among Iranian graduate students of education. Journal of Second Language Writing, 6, 105-137.

Roca de Larios, J. 1999. Cognitive processes in L1 and L2 writing: A cross-sectional study. Unpublished doctoral thesis, University of Murcia, Spain.

Rubin, J., Chamot, A.U., Harris, V. and Anderson N.J. 2007. Intervening in the use of strategies. In A.D. Cohen and E. Macaro (Ed.), Language Learner Strategies, pp. 141-160. Oxford: OUP.

Sasaki, M. 2000. Toward an empirical model of EFL writing processes: An exploratory study. Journal of Second Language Writing, 9, 259-291.

Sasaki, M. 2004. A multiple data analysis of the 3.5-year development of EFL student writers. Language Learning, 54, 525-582.

Sasaki, M. and Hirose, K. 1996. Explanatory variables for EFL students' expository writing. Language Learning, 46, 137-174.

Schwarzer, D. 2004. Student and teacher strategies for communicating through dialogue journals in Hebrew: A teacher research project. Foreign Language Annals, 37, 77-84.

Sengupta, S. 2000. An investigation into the effects of revision strategy instruction on L2 secondary school learners. System, 28, 97-113.

Scollon, S. 1999. Not to waste words or students: Confucian and Socratic discourse in the tertiary classroom. In E. Hinkel (Ed.), Culture in Second Language Teaching and Learning, pp. 13-27. New York: Cambridge University Press.

Victori, M. 1995. EFL writing knowledge and strategies: An integrative study. Unpublished doctoral thesis, Universidad Autónoma de Barcelona, Spain.

Wang, W. and Wen, Q. 2002. L1 use in the L2 composing process: An exploratory study of 16 Chinese EFL writers. Journal of Second Language Writing, 11, 225-246.

Whalen, K. and Ménard, N. 1995. L1 and L2 writers' strategic and linguistic knowledge: A model of multiple-level discourse processing. Language Learning, 45, 381-418.

Wolfersberger, M. 2003. L1 to L2 writing process and strategy transfer: A look at lower proficiency writers. TESL-EJ Journal, 7, 1-12.

Wong, A.T.Y. 2005. Writers' mental representations of the intended audience and of the rhetorical purpose for writing and the strategies that they employed when they composed. System, 33, 29-47. 
Woodall, B.R. 2002. Language-switching: Using the first language while writing in a second language. Journal of Second Language Writing, 11, 7-18.

Wu, S. 1995. Transfer in Chinese students' academic English writing. Unpublished doctoral thesis, Northern Arizona University, Flagstaff, Arizona, USA.

Zainuddin, H. and Moore, R.A. 2003. Audience awareness in L1 and L2 composing of bilingual writers. TESL-EL, 7, 1-19. 